Supporting Information

\title{
Synthesis and Applications of Magnetic Nanocomposite Catalysts
}

\author{
Dong Kee Yi, Su Seong Lee, and Jackie Y. Ying*
}

\section{Contents:}

XRD patterns of $\mathrm{SiO}_{2} / \mathrm{Fe}_{2} \mathrm{O}_{3}$ support (Figure SI1), p. S-2

TEM micrograph of $\mathrm{Pd} / \mathrm{SiO}_{2} / \mathrm{Fe}_{2} \mathrm{O}_{3}$ synthesized without affinity ligands (Figure SI2), p. S-3

Detailed experimental procedures, p. S-4 


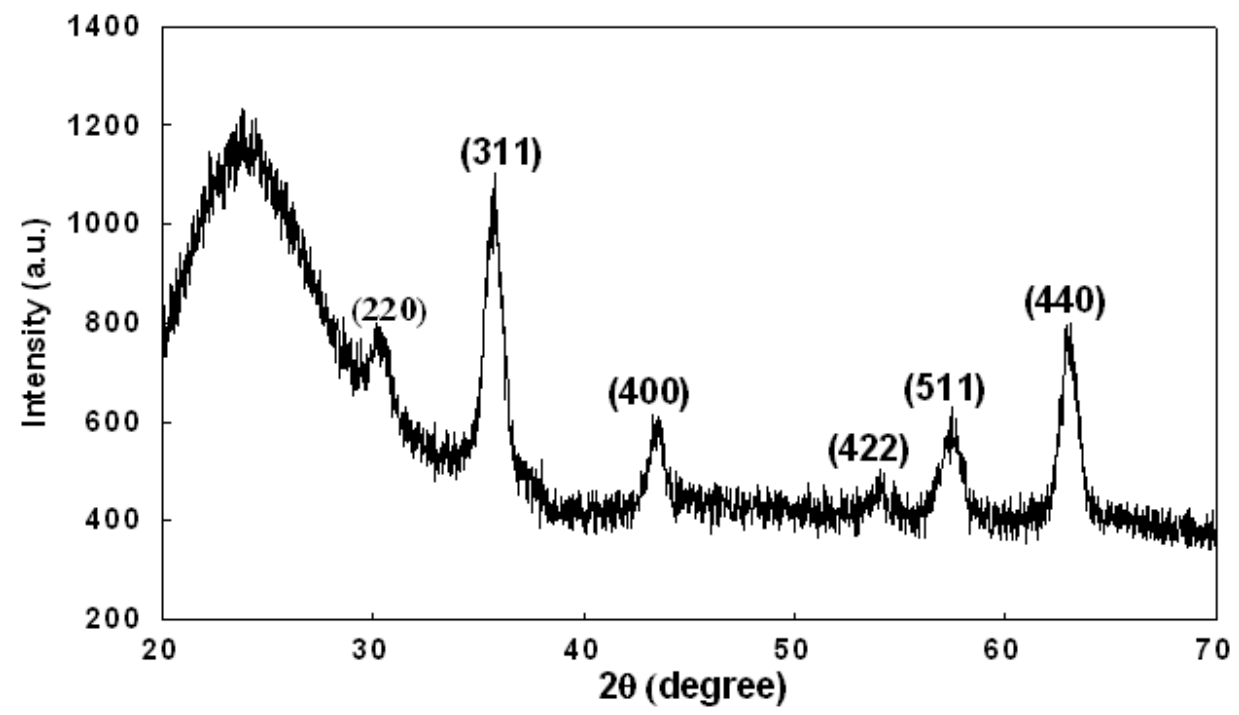

Figure SI1. XRD patterns of $\mathrm{SiO}_{2} / \mathrm{Fe}_{2} \mathrm{O}_{3}$ support. 


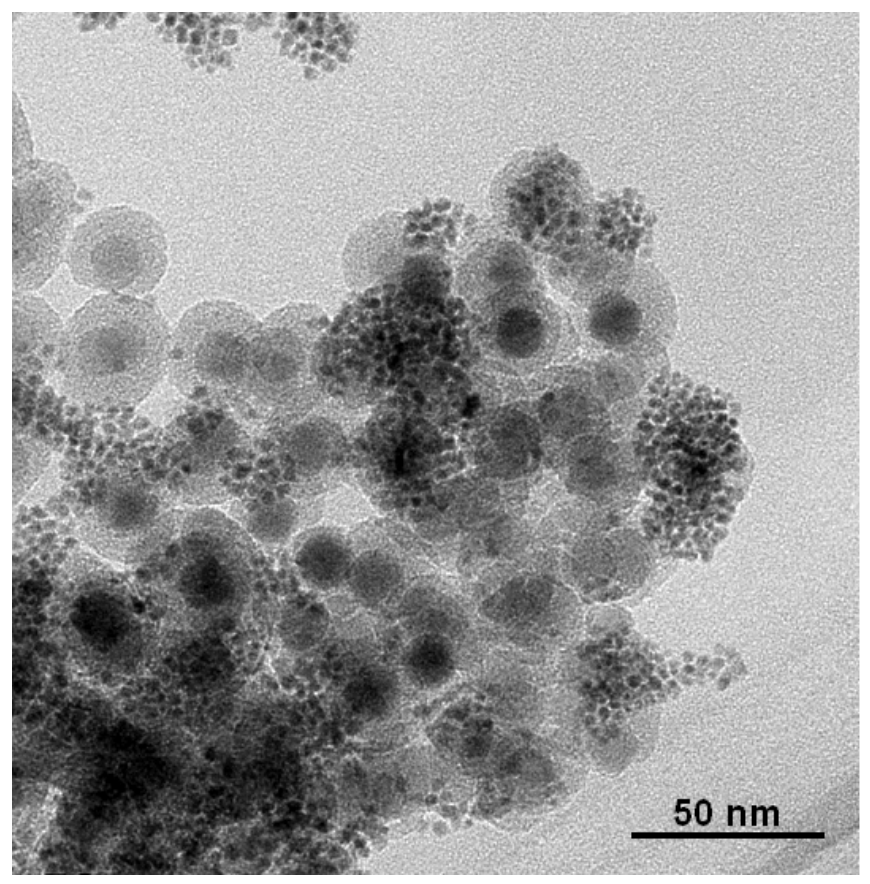

Figure SI2. TEM micrograph of $\mathrm{Pd} / \mathrm{SiO}_{2} / \mathrm{Fe}_{2} \mathrm{O}_{3}$ synthesized without affinity ligands. 


\section{Detailed Experimental Procedures}

\section{General}

Igepal CO-520, tetraethylorthosilicate (TEOS), $\mathrm{Pd}(\mathrm{OAc})_{2}$, and $\mathrm{Pd} / \mathrm{C}(10 \%)$ were purchased from Aldrich, and used without further purification. Discover ${ }^{\circledR}$ Labmate $^{\mathrm{TM}}$ from CEM was used for microwave synthesis. For TEM analysis on Tecnai ${ }^{\text {TM }}$ (Philips, $200 \mathrm{kV}$ ), samples were dispersed in ethanol and placed on carbon grids. Elemental analysis of Pd was performed by EDX interfaced with TEM, and by ICP-MS (HP 4500). Powder XRD patterns were obtained with Xpert ${ }^{\mathrm{TM}}$ (Panalytical).

\section{Synthesis of $\mathrm{Pd} / \mathrm{SiO}_{2} / \mathrm{Fe}_{2} \mathrm{O}_{3}$}

$\mathrm{SiO}_{2} / \mathrm{Fe}_{2} \mathrm{O}_{3}$ with $20 \mathrm{~nm}$-thick silica shell was synthesized by reverse microemulsion. Polyoxyethylene(5)nonylphenyl ether (35 g, 0.084 mol, Igepal CO-520) was dispersed in cyclohexane (440 ml, ACS grade) by sonication. Next, $40 \mathrm{ml}$ of $\gamma$ - $\mathrm{Fe}_{2} \mathrm{O}_{3}$ nanoparticles dispersed in cyclohexane $(0.4 \mathrm{mg} / \mathrm{ml})$ were added. The resulting mixture was vortexed until it became transparent. Ammonium hydroxide $(29.4 \%, 3.5 \mathrm{ml}$ ) was then added to form a transparent, brown reverse microemulsion. Lastly, TEOS (2 $\mathrm{ml})$ was added. The mixture was gently vortexed, and the reaction was continued for 2 days at room temperature. The resulting $\mathrm{SiO}_{2} / \mathrm{Fe}_{2} \mathrm{O}_{3}$ nanocomposite particles were precipitated by adding methanol, and collected by centrifuging at $7000 \mathrm{rpm}$. The collected $\mathrm{SiO}_{2} / \mathrm{Fe}_{2} \mathrm{O}_{3}$ nanoparticles were redispersed in ethanol, and purified by sonication and centrifugation. The ethanol washes and centrifugation were repeated three times. The nanoparticles obtained were dried in vacuиo.

$225 \mathrm{mg}$ of $\mathrm{SiO}_{2} / \mathrm{Fe}_{2} \mathrm{O}_{3}$ were functionalized with $0.045 \mathrm{mmol}$ of MPS and AAPS by refluxing in toluene for $30 \mathrm{~h}$ to give $\mathrm{HS}-\mathrm{SiO}_{2} / \mathrm{Fe}_{2} \mathrm{O}_{3}$ and $\mathrm{H}_{2} \mathrm{~N}-\mathrm{SiO}_{2} / \mathrm{Fe}_{2} \mathrm{O}_{3}$, respectively. The functionalized $\mathrm{SiO}_{2} / \mathrm{Fe}_{2} \mathrm{O}_{3}$ supports were then treated with $\mathrm{Pd}(\mathrm{OAc})_{2}$ under microwave $(300 \mathrm{~W})$ for $15 \mathrm{~min}$. The resulting black colloidal particles were collected by a magnet, washed with toluene 3 times, and dried in vacuuo. Microwave was used to form palladium particles rapidly (i.e. within a few minutes), and to produce a uniform distribution of finer palladium particles with well-defined crystallinity. Thermal decomposition of palladium acetate in organic solvents could also be used to derive slightly larger palladium nanoparticles over a longer reaction period.

\section{Hydrogenation of Nitrobenzene}

For the recycling studies, $2 \mathrm{mmol}$ of nitrobenzene were reacted in $6.5 \mathrm{ml}$ of 2-propanol over $2.2 \mathrm{mg}$ of $\mathrm{Pd} / \mathrm{H}_{2} \mathrm{~N}-\mathrm{SiO}_{2} / \mathrm{Fe}_{2} \mathrm{O}_{3}\left(2 \mathrm{mmol} \mathrm{Pd}\right.$ ) under room temperature and $1 \mathrm{~atm}$ of $\mathrm{H}_{2}$ for 90 min. The turnover number was set at 1000 for $100 \%$ conversion in each run. The product was 
filtered with $200 \mathrm{~nm}$-pore filter, and analyzed by GC. $\mathrm{Pd} / \mathrm{SiO}_{2} / \mathrm{Fe}_{2} \mathrm{O}_{3}$ catalysts were collected by a magnet, and washed with 2-propanol before its reuse in the next run. 